\title{
'Shhh! Please don't tell...' Confidentiality in child and adolescent mental health
}

\author{
Aaron K. Vallance
}

\begin{abstract}
SUMMARY
Confidentiality in child and adolescent mental health is a complex and often challenging matter. Not only do young people frequently present to services in situations of risk, they often prefer to keep information confidential from parents and/or other professionals. This article explores confidentiality in the context of child and adolescent mental health services (CAMHS), particularly when the clinician is having to make decisions on whether to maintain or to breach it. Ethical principles (both deontological and consequentialist) and legal and regulatory frameworks (relating to human rights, case law and General Medical Council guidance) are outlined. Four hypothetical case scenarios are used to illustrate how to apply such principles: when a young person seeks confidential access to treatment, and when he or she discloses information that could signify a risk to self, to others or from others. Finally, practical suggestions on how to share information are explored.
\end{abstract}

\section{LEARNING OBJECTIVES}

- Outline some relevant ethical principles and legal/ regulatory frameworks, and apply them when weighing up the pros and cons of maintaining or breaching confidentiality

- Apply strategies for breaching confidentiality that balance the need to share information appropriately against the need to preserve therapeutic rapport and engagement

- Judge how one's own ethical perspectives might influence decision-making in confidentiality dilemmas

\section{DECLARATION OF INTEREST}

None

Confidentiality involves keeping private the information disclosed by someone using services. They may well consent to the sharing of information, for example with their family and/ or other professionals. However, dilemmas arise when they refuse the sharing of information, even though breaching confidentiality could potentially protect or benefit that person or others.
Confidentiality is a complex matter in clinical practice, and particularly so in child mental healthcare. First, young people frequently present to child and adolescent mental health services (CAMHS) with sensitive and risk-related situations, including self-harm, suicidality, sexual behaviour, and alcohol and substance use. Second, young people often prefer such information not to be shared with parents and/or other professionals. Third, the child's level of competency may need to be taken into consideration.

Confidentiality represents an opportunity to engage a young person in developing a trustful engagement with services, with long-term positive consequences for their mental health. The development of autonomy is also an important task of adolescent maturity, and the opportunity to engage with services in a confidential, supportive manner can be an empowering experience in its own right. However, the need to decide whether to maintain or breach a young person's confidentiality can face clinicians without warning and immerse them in a quicksand of legal, ethical and clinical dilemmas.

This article explores various ethical, legal, regulatory and practical issues regarding confidentiality that can present in CAMHS, using four case scenarios (Box 1) to illustrate the application of principles in practice.

\section{Ethics}

Ultimately, clinicians want to do the right thing. The challenge of confidentiality is that it can frequently tear them in different directions when deciding what the right thing actually is. On one hand, it can feel right to respect a young person's confidentiality in order to maintain trust. On the other hand, it feels important to protect a young person from harm, and if breaching confidentiality is necessary for protection, then so be it. But what if the process of breaching confidentiality could exacerbate the risk? And what about parents' rights - should they not be given information to enable them to protect their child? Dilemmas arise when such ethical values conflict. For any
Aaron K. Vallance is a consultant in child and adolescent psychiatry in Surrey CAMHS (Surrey and Borders Partnership NHS Foundation Trust) and an honorary clinical senior lecturer in the Faculty of Medicine (Faculty of Education), Imperial College London. He has an MA (Oxon) in Psychology, Philosophy and Physiology and a Masters in Education. His specialist interests include medical education, and he has written on various aspects of child and adolescent psychiatry. Correspondence Dr Aaron K. Vallance, South Surrey CAMHS Community Team, Bray Road, Guildford GU2 7L0, UK. Email: aaron.vallance@sabp.nhs.uk 
BOX 1 Four hypothetical case scenarios involving a decision on whether or not to breach confidentiality

\section{Ahmed}

Ahmed is a 15-year-old boy who presents with anxiety disorder. His school counsellor remains concerned despite a package of cognitive-behavioural therapy; Ahmed's anxiety is significantly affecting his work. He arrives in the clinic by himself. Ahmed has read information online about medication with selective serotonin reuptake inhibitors and wants to give it a go. However, he is clear that he does not wish his family to know anything: they have other stresses and he does not wish to worry them further.

\section{Adele}

Adele is a 15-year-old girl attending CAMHS with depressive disorder. In an individual session, she reports self-harming by cutting regularly for several weeks. She also has occasional suicidal ideation, although has never had any firm intent or plan. She begs her doctor not to tell her family. She is concerned that if they found out, they would just get angry.

Frank

Frank is a 16-year-old boy recently diagnosed with autism spectrum disorder.
During the assessment, he reports that for several months he has had repeated thoughts of killing people. There is no forensic history or history of aggression. $\mathrm{He}$ is not overly distressed by these thoughts, but recognises that others might be concerned if they knew about them. The potential targets change frequently; they tend to be peers at college whom he perceives as bullies. There is currently no specific target in mind, but Frank thinks it is possible he might do something sometime in the future.

\section{Katie}

Katie is a 14-year-old girl attending CAMHS with an eating disorder. In an individual session, she discloses that she was drunk at a party and a 19-year-old man had sex with her. She remembers little, although reports that the man, who was vaguely connected to her wider peer group, had been sending her sexually related messages online. She feels distressed at what happened and blames herself. She does not wish anyone to know; she feels embarrassed and does not want to cause trouble.

given situation, some sort of ethical calculation is needed to determine the most appropriate course of action.

\section{The deontological and consequentialist positions}

Two distinct strains of moral philosophy have historically dominated the ethical landscape. Deontological ethics, such as that proposed by Kant, argues that the morality of an action is to be judged by whether the action is in itself right or wrong, based on a wider system of rules, rights or doing one's duty (Kant 1964). In contrast, consequentialist or teleological ethics, such as utilitarianism proposed by Bentham and Mill, argues that the morality of an action is based solely on all the good and all the harm that consequentially arises (Mill 1863). Although these arguments have further evolved in contemporary moral philosophy, both perspectives still remain relevant when considering confidentiality issues.

\section{Medical ethics: beneficence, non-maleficence and autonomy}

Specific ethical principles have also been proposed for medical practice (Beauchamp 2001).

Beneficence involves acting so as to improve the patient's health or welfare, whereas conversely nonmaleficence involves acting so as to avoid harm. Autonomy involves respecting and supporting the right of patients to make their own healthcare choices. These principles can also be viewed from both deontological and consequentialist positions. The intrinsic duty of a clinician acting out of good will, striving to do good and avoid harm for the patient, could be seen deontologically as a good in itself, represented archetypically by the Hippocratic Oath. A consequentialist position would instead place the ethical onus on the specific situation, calculating a 'harm/benefit ratio' of consequences.

When beneficence and non-maleficence are applied to confidentiality issues, preserving confidentiality may benefit the young person by encouraging disclosure of all relevant clinical information, enabling the clinician to act effectively (Ford 2004). Furthermore, protecting confidentiality may enhance both the therapeutic relationship and service engagement, with potentially long-term benefits to health and risk (Guedj 2009). In contrast, when the clinician learns of a significant risk, breaching confidentiality and sharing information with parents or other authorities may help them minimise the risk of harm.

One may need to think beyond the individual situation and consider principles more universally. For example, if young people have little faith in the confidentiality of health services, this may lead them to keep sensitive but important information hidden or may even prevent them from attending at all. Guidance from the General Medical Council (GMC 2007) specifically requests clinicians to value the wider principle of 'society's interest in maintaining trust between doctors and patients' (p. 20) whenever a clinician deliberates on an individual case. In contrast, another universal principle could be applied to supporting the need to breach confidentiality: societies where information is freely shared within families and between services may help deter those who might otherwise abuse.

Autonomy is arguably more deontological in character. A young person's right to confidentiality lies in their right to autonomy; the freedom to make meaningful choices about one's own welfare is an important aspect of being human. With this argument, whether the choices ultimately prove good or bad is less important than the intrinsic freedom to make one's own choices. In fact, it is often through seemingly adverse outcomes that individuals learn from their mistakes and develop as human beings. 
Developing autonomy and individuation from one's parents is particularly critical in adolescence (Erikson 1968). Confidentiality brings these tensions to the forefront: Tebb (2011) notes the important role that clinicians can play both in helping young people in the transition to adulthood, encouraging them to take greater responsibility for making decisions about their own health, and in supporting parents accept the increasing independence of their children. Applewhite \& Joseph (1994) observe that maintaining confidentiality indicates to both the young person and their parents that the child has a right to privacy and is capable of independent thought: 'this value fosters the development of the separation and individuation needed for growth and development'.

Not all societies share autonomy as a fundamental right. Some cultures have a more collectivist orientation, where family elders bear more influence on an individual's decision-making (G Durà-Vilà, personal communication, 2015). Applewhite \& Joseph meanwhile argue for a hierarchy of principles: safety and security, then autonomy, then parental autonomy and privacy (Applewhite 1994).

Finally, clinicians must always be mindful of their own ethical values, built up from their experiences and their cultural background (Applewhite 1994). Ethical judgements are significantly subjective processes, and such biases could influence us. We must reflect on our own ethical stance when making decisions that impact so heavily on others.

\section{Legal and regulatory frameworks}

Various legal frameworks attempt to apply such ethical principles. The United Nations Convention on the Rights of the Child (UNCRC) states that children have the right to express their views freely in all matters affecting them, in accordance with their age and maturity (Article 12). The UNCRC stipulates that, for any action relating to a child, their best interests must be considered. However, who decides what is in their best interests - the child, their parents or the State - is perhaps ambiguous, as is what happens when rights to autonomy conflict with rights to protection (Iltis 2010).

In England and Wales, the Human Rights Act 1998 incorporates the European Convention for the Protection of Human Rights and Fundamental Freedoms (European Convention on Human Rights, ECHR), Article 8(1) of which specifies that everyone has the right to a private and family life. Preserving confidentiality respects the young person's right to a private life. In contrast, sharing information with parents respects the parental right to a family life, so that they can fulfil their responsibilities as parents. Article 8(1) could therefore be applied either way in a confidentiality dilemma, although many would generally prioritise a child's right to privacy over parental rights to know information about their child (Applewhite 1994). However, Article 8(2) defines situations which may supersede Article $8(1)$, such as to prevent crime or protect a person's health and welfare.

Most legislation relating to confidentiality arises from common law (i.e. case law that becomes accepted as legal). The common law duty of confidentiality mandates that information shared between a client and a professional (such as in the patient-doctor relationship) is generally confidential. However, both common law and Article 8(2) of the ECHR indicate that this duty is not absolute and disclosure can be justified when there is overriding 'public interest' (Robshaw 2004).

When it comes to children who do not have the maturity or understanding to make a decision, confidentiality can be breached if this is deemed to be in their best interests, reflecting the UNCRC. Meanwhile the Family Law Reform Act 1969 mandates that 16- to 17-year-olds can consent to medical treatment. For under-16-year-olds, case law on consent generally derives from Gillick $v$ West Norfolk and Wisbech Area Health Authority [1986] (subsequently referred to as Gillick), where the House of Lords judged that children could consent so long as they had sufficient 'competency' (Table 1). These legal frameworks,

\section{TABLE 1 Key examples of case law relating to children's rights to confidentiality}

\begin{tabular}{|c|c|c|}
\hline Case & Claim & Outcome \\
\hline Gillick $^{\mathrm{a}}$ & $\begin{array}{l}\text { A mother requested that her local } \\
\text { health authority not provide family } \\
\text { planning services to her daughters, } \\
\text { who were under } 16 \text { years old, without } \\
\text { her consent. }\end{array}$ & $\begin{array}{l}\text { The mother's claim was rejected. The House } \\
\text { of Lords determined that the health authority } \\
\text { could give treatment to under- } 16 \text {-year-olds } \\
\text { if they were deemed competent to make the } \\
\text { treatment decision. Competence is deemed } \\
\text { if the child has 'sufficient understanding } \\
\text { and intelligence to enable him or her to } \\
\text { understand fully what is proposed', which } \\
\text { encompasses the ability to weigh the } \\
\text { benefits and risks of medical treatment, and } \\
\text { to manage any family and peer pressure. It } \\
\text { is generally assumed that an obligation of } \\
\text { confidence is owed to competent children. }\end{array}$ \\
\hline$A x o n^{b}$ & $\begin{array}{l}\text { A mother claimed that it would not } \\
\text { be in the bests interests of an under- } \\
16 \text {-year-old to receive an abortion } \\
\text { without a parent's knowledge, as this } \\
\text { would deprive the girl of the essential } \\
\text { support and aftercare that a parent } \\
\text { would provide. }\end{array}$ & $\begin{array}{l}\text { The mother's claim was rejected. This } \\
\text { confirms that an obligation of confidence is } \\
\text { owed to competent children, as underpinned } \\
\text { by Article } 8 \text { of the European Convention on } \\
\text { Human Rights. }\end{array}$ \\
\hline
\end{tabular}

a. Gillick v West Norfolk and Wisbech Area Health Authority [1986] AC 112.

b. $R$ (Axon) v Secretary of State for Health [2006] EWCA 37. 
however, more explicitly focus on children's rights to consent to treatment as opposed to their rights to confidentiality (Cave 2009). However, in Gillick, Lord Scarman's statements indicate that such rights could be viewed equivalently. For example, he states that once a child is 'competent', then 'parental rights yield to the child's right', and this has since been interpreted to encompass rights to confidentiality.

The case law that most explicitly relates to children's rights to confidentiality is $R$ (Axon) $\mathrm{V}$ Secretary of State for Health [2006] (subsequently referred to as Axon) (Table 1). Justice Silber's High Court judgment noted that the ECHR and the UNCRC:

\begin{abstract}
'show why the duty of confidence owed by a medical professional to a competent young person is a high one and which therefore should not be overridden except for a very powerful reason. In my view, although family factors are significant and cogent, they should not override the duty of confidentiality owed to the child.'
\end{abstract}

However, it does beg the question as to what constitutes a 'very powerful reason' to override a competent young person's right to confidentiality. In Axon, the children were appropriately seeking beneficent access to healthcare. What if a child instead wanted to keep confidential information that would indicate that they, or others, were in danger: would it still be in the public interest to keep this type of information confidential? The GMC defines 'public interest' as when:

'the benefits which are likely to arise from the release of information outweigh both the child or young person's interest in keeping the information

B0X 2 When confidentiality can be breached

In the following examples confidentiality can be breached in order for authorities to receive notification, in accordance with legal or regulatory statutes

Health and Social Care Act 2008

Death of a person who has been receiving a health or social care service

Death or unauthorised absence of someone detained (or liable to be detained) under the Mental Health Act 1983

Application to deprive a person of their liberty (under the Mental Capacity Act 2005) Placement of a child on an adult psychiatric ward

Other frameworks

Security of medical records (Data Protection Act 1998

Aiding police in matters relating to terrorism (Terrorism Act 2006)
Aiding regulatory bodies as part of their duties to investigate complaints, accidents or health professionals' fitness to practise (GMC 2007)

When ordered by a judge or presiding officer of a court, as long as the information is relevant (GMC 2009)

Victims of mentally disordered offenders detained in hospital have a right to receive information regarding the patient's discharge (Domestic Violence, Crime and Victims Act 2004)

Disclosure of information (e.g. to mental health review tribunals) for statutory purposes under the Mental Health Act 1983 confidential and society's interest in maintaining trust between doctors and patients. You must make this judgement case by case, by weighing up the various interests involved [...] You should consider the benefits and possible harms that may arise from disclosure [...] You should disclose information [...] to protect the child, or someone else, from risk of death or serious harm' (GMC 2007: pp. 20 \& 21).

Example situations cited include a child at risk of abuse or involved in behaviour that might put them or others at risk of serious harm (for example, serious addiction, self-harm or joyriding) or where the information would help in the prevention, detection or prosecution of serious crime (GMC 2007: p. 21). There are also situations where confidentiality needs to be breached in accordance with legal or regulatory statutes (Box 2).

The GMC's position here is considerably consequentialist: decisions involve calculating the consequent harms and benefits of disclosure versus non-disclosure. The position allows the clinician significant leeway. First, the guidance invites clinicians themselves to weigh up the benefits and risks. Different clinicians may well prioritise different factors, on the basis of their own wider ethical perspectives. Second, clinicians may vary in how they judge 'risk' and what harm they count as 'serious'. As Jellinek (2010) notes, 'where judgment must play a role [...] is in dissecting different degrees of danger. You may want to hold in confidence the idea that a teen has contemplated initiating a sexual relationship, while never hesitating to consult with parents about real and present dangers, such as the news that a child is planning to run away [or] is suicidal'.

Ultimately, there are various reasons why a child may wish for information to be kept confidential. They may feel that the information itself is too sensitive and personal, particularly if it would cause them embarrassment. They may worry about how their parents will react, particularly if they are already worried about their parents' mental health or that disclosure would lead to family conflict. They may worry parents will intervene in a seemingly unhelpful way. Disclosure may therefore result in distress or other negative feelings that actually lead to an exacerbation of risk. The GMC guidance specifically notes that clinicians should consider the 'possible harms that may arise from disclosure' (GMC 2007).

Likewise, there are a good reasons why the sharing of information with parents can help a young person. Parents are well placed to support their children, and the Children Act 2004 endows them with an important role in both safeguarding and providing guidance to their children. The sensitive sharing of information could represent an opportunity to help support and develop 
family communication. Even if confidentiality is maintained, the GMC advises that "you should not refuse to listen to a patient's [...] carers or others on the basis of confidentiality. Their views or the information they provide might be helpful in your care of the patient. You will, though, need to consider whether your patient would consider you listening to the concerns of others [...] to be a breach of trust' (GMC 2009: p. 26).

\section{Case scenarios}

The balance of ethical, legal and regulatory principles summarised in Table 2 is applicable in each of the case scenarios presented earlier (Box 1) depicting a young person wanting to keep information confidential. Deontological arguments generally support the young person's right to confidentiality in terms of their rights to autonomy and privacy, and this is further supported by case law such as Gillick and Axon. Parents also have rights to fulfil their parental responsibilities under the same Article 8(1) of the ECHR and under the Children Act 2004. Furthermore, Article 8(2) of ECHR can supersede Article 8(1) in order to protect someone's health or welfare. A balancing act in relation to the specific context needs to be considered, since consequentialist and legal arguments may vary depending on the case.

\section{Access to treatment}

The first scenario involves Ahmed, the 15-year-old with anxiety disorder who wants medication, but does not want his parents to know. This situation echoes that of Gillick, assuming that Ahmed is Gillick-competent. Although the original case related to accessing contraception, this case law now applies to any medical treatment. If the child is competent to access treatment, Gillick also implies that they would be competent to access it confidentially, and this is consolidated further in case law through Axon.

However, even if the legal argument justifies Ahmed's rights to confidentiality, the clinician also needs to make clinical and ethical judgements. The treatment would need to be warranted in terms of its potential effectiveness ('beneficence') significantly outweighing its potential for sideeffects ('non-maleficence'). Furthermore, Ahmed needs the required maturity and intelligence not just to understand the treatment (as per Gillick-competency), but to manage the practical aspects of attending appointments, picking up prescriptions, and storing and administering the medicine safely. What is the risk of him potentially misusing the medicine, even using it to self-harm or in a suicide attempt? All these judgements need to be made in terms of calculating beneficence and non-maleficence.

If it is felt that legally Ahmed is competent, that clinically the benefits outweigh the risks, and that practically access is feasible, then the treatment should arguably proceed in confidence. However, the GMC would generally advise the clinician still to encourage Ahmed to involve his parents, even if ultimately his confidentiality is respected (GMC 2007).

TABLE 2 A summary of principles to consider when deciding whether to maintain or breach confidentiality of a competent young person

\begin{tabular}{|c|c|c|}
\hline & Principles in favour of maintaining confidentiality & Principles in favour of breaching confidentiality \\
\hline Deontological or rights-based & $\begin{array}{l}\text { A competent young person's right to confidentiality lies in their right } \\
\text { to autonomy, and the developing of autonomy is an important part of } \\
\text { adolescence } \\
\text { Individuals have a right to a private life (Article 8(1) of ECHR) } \\
\text { Legal rights enshrined in case law (Gillick and Axon) }\end{array}$ & $\begin{array}{l}\text { Parents have rights in order to fulfil their responsibilities as } \\
\text { parents (Children Act 2004) } \\
\text { Parents have a right to a family life (Article 8(1) of ECHR) }\end{array}$ \\
\hline $\begin{array}{l}\text { Consequentialist relating to } \\
\text { the individual attendee }\end{array}$ & $\begin{array}{l}\text { Encourages the young person attending the service to disclose relevant } \\
\text { clinical information to enable the clinician to act in the most clinically } \\
\text { effective way: 'Without the trust that confidentiality brings, children } \\
\text { and young people might not seek medical care and advice, or they might } \\
\text { not tell you all the facts needed to provide good care' (GMC 2007: p. 18) } \\
\text { Protects/enhances the therapeutic relationship and the attendee's } \\
\text { engagement, with potentially long-term health benefits } \\
\text { Disclosure by the attendee might cause stress or conflict in the family, } \\
\text { which might exacerbate risk }\end{array}$ & $\begin{array}{l}\text { Enlists help of parents or authorities to help safeguard the } \\
\text { young person, thereby minimising the risk of harm } \\
\text { 'You should disclose information if this is necessary to } \\
\text { protect the child or young person [...] from risk of death or } \\
\text { serious harm' (GMC 2007: p. 20) } \\
\text { Represents an opportunity to help support and develop } \\
\text { family communication }\end{array}$ \\
\hline $\begin{array}{l}\text { Consequentialist relating to } \\
\text { the wider society }\end{array}$ & $\begin{array}{l}\text { If young people in society do not in general trust in the confidentiality of } \\
\text { health services, they might keep important information hidden or might } \\
\text { not attend at all } \\
\text { 'A disclosure is in the public interest if the [likely] benefits [...] outweigh } \\
\text { both the child or young person's interest in keeping the information } \\
\text { confidential and society's interest in maintaining trust between doctors } \\
\text { and patients' (GMC 2007: p. 20) } \\
\text { 'Confidential medical care is recognised in law as being in the public } \\
\text { interest' (GMC 2009: p. 16) }\end{array}$ & $\begin{array}{l}\text { Societies where information is freely shared within families } \\
\text { and between services may help deter those who might } \\
\text { otherwise abuse } \\
\text { 'You should disclose information [...] when there is an } \\
\text { overriding public interest in the disclosure' (GMC 2007: } \\
\text { p. 19) }\end{array}$ \\
\hline
\end{tabular}


When considering Ahmed, we must also bear in mind the wider importance of trust between clinician and patient in society. In Axon, Justice Silber noted that between the decision of the Court of Appeal in Gillick (which originally upheld the mother's claim) and that of the House of Lords (which ultimately rescinded it), the number of under-16-year-olds who sought contraception fell by almost one-third.

In fact, research has convincingly shown that protecting confidentiality can improve, and restricting confidentiality can diminish, the likelihood that adolescents access healthcare (Cheng 1993; Ford 1997, 1999; Klein 1999; Carlisle 2006). In one survey of adolescent girls attending family planning clinics, $60 \%$ said that they would stop using sexual health services if parents were notified of contraceptive prescribing (Reddy 2002). In two large surveys, approximately one-quarter of adolescents reported not attending needed health services, 35\% of them because they did not wish their parents to know (Kaplan 1998; Logan 2002). Lehrer et al's survey found that $10.5 \%$ of boys and $14.3 \%$ of girls who reported not accessing healthcare services gave concern about confidentiality as their reason, particularly if they had high depressive symptoms and suicidal ideation (Lehrer 2007).

Parents meanwhile vary in their attitudes towards adolescent rights to confidential consultations. Magnusson et al (2007) showed that, although $92 \%$ of parents agreed that 16 -year-olds should always have access to confidential appointments, this figure dropped to $52 \%$ when they considered under-16-year-olds. Ethnic and religious factors may also influence parental attitudes (G DuràVilà, personal communication, 2015).

\section{Risk to self}

Now let us turn to Adele, the 15-year-old with depression, self-harm and suicidal ideation, but no firm suicidal intent or plan, who does not wish her parents to know. This is a common scenario presenting to CAMHS services, and the principles illustrated in Table 2 apply.

GMC guidance advises that information can be disclosed if there is an overriding public interest in the disclosure in order to protect the child from risk of death or serious harm, including through self-harm (GMC 2007). A risk-benefit analysis is needed: 'look to the consequences and determine which action produces the greatest proportionate good' (Applewhite 1994). One needs to decide whether Adele's cutting and suicidal ideation, without suicidal intent, would constitute a risk of serious harm. On one hand, superficial cutting may arguably constitute a low risk of serious harm. Furthermore, given the lack of suicidal intent, and considering that about $30 \%$ of adolescents report having had suicidal ideation (the overwhelming majority of whom do not attempt suicide) (Evans 2005), again the risk of serious harm here does not appear high. Yet, research also indicates that selfharm is a risk factor for more significant suicide attempts, albeit in the longer term, so this would also need to be factored in. In addition, many other static and dynamic factors may influence risk, for example history of suicide attempts, mental disorder, adverse childhood events, interpersonal difficulties, low educational achievement, and drug and alcohol use (Hawton 2012).

The clinician needs to evaluate whether breaching confidentiality would ultimately reduce or increase risk. Although its aim would be to involve parents to help protect their child and thus reduce risk, the potential for risk exacerbation also needs consideration. Breaching confidentiality could lead to: increased stress for Adele, real or perceived stress for her parents, increased family conflict, damage to therapeutic rapport/effectiveness and disengagement from services.

The risk of such negative consequences is implicated in research. The risk that young people will not disclose sensitive issues such as substance use, mental illness and sexual behaviours (Carlisle 2006) and that they might disengage from services altogether (Ford 1997; Thrall 2000) is significant if they feel that their confidentiality may be breached. This in turn could have a negative impact on the adolescent's longer-term health and overall risk.

In contrast, research shows that parents value being told important information about their child. In one study, $87 \%$ of parents interviewed wished for issues concerning their adolescent children's mental health to be disclosed to them (Duncan 2011). However, $77 \%$ of the parents also acknowledged the value of adolescent confidentiality, which, as Tebb (2011) notes, reflects some discordance in attitudes. Another study (Carlisle 2006) reported that parents unanimously wished to be informed about their adolescent children's health and risky behaviour, often citing their 'right to know'.

Various studies have surveyed clinicians' attitudes on what influences them to breach confidentiality when a child expresses risk to self. Clinical child psychologists (Sullivan 2002) and school counsellors (Sullivan 2008) generally place much weight on the immediacy, seriousness, frequency, intensity and duration of the risky behaviour, and the need to protect the child. More moderate importance was attached to the negative effects of breaching on the family and 
on service attendance. A survey of clinical child psychologists found a significant lack of consensus in attitudes but the authors reflected that 'ethical codes and guidelines allow for (and result in) individual differences in decision making' (Rae 2002). Anecdotal experience of CAMHS services suggests that clinicians do hold disparate views on confidentiality, despite a general appreciation of its underlying principles, ethics and regulations.

If Adele's clinician decides to breach confidentiality, they would need to explain to her why they think it necessary, as well as monitoring her for any negative consequences and supporting her and her family so as to minimise any exacerbation of risk. If the clinician decides to maintain confidentiality, they could still encourage and work with Adele to help her to continue reflecting on the sharing of information with her parents (GMC 2007).

\section{Risk to others}

Let us now consider Frank, the 16-year-old with autism spectrum disorder and repetitive thoughts of killing people, but no specific intent or target. In contrast to the two previous scenarios, the potential risk is to others and so sharing information with other authorities (e.g. the police and/or children's services) may need consideration.

The GMC guidance states that 'disclosure without consent may be justified in the public interest if failure to disclose may expose others to a risk of death or serious harm' (GMC 2009: p. 21). It refers to the NHS code of practice on confidentiality in clarifying which serious crimes this may encompass:

'Murder, manslaughter, rape, treason, kidnapping, child abuse or other cases where individuals have suffered serious harm may all warrant breaching confidentiality. [...] In contrast, theft, fraud or damage to property where loss or damage is less substantial would generally not warrant breach of confidence' (Department of Health 2003a: p. 35)

Had Frank actually made specific threats against a person, with some intent to kill, then confidentiality should be breached, and police and children's services informed, in accordance with GMC guidelines and ethical principles (since safety and protection would generally supersede rights to autonomy). However, the scenario is less clear-cut since Frank is currently not making any specific threats nor is there intent. One could argue that the potential outcome is so serious, one should have a low threshold, so that confidentiality should be breached even if the likelihood of him acting on his thoughts is low. Police and children's services might even offer support, which could attenuate risk. On the other hand, it could be argued that the shortterm risk is low, and that breaching confidentiality might have a negative impact on his rights, his healthcare engagement and perhaps his social situation, any of which could exacerbate risk.

The specificity of intent and threat is legally important. In Palmer $v$ Tees Health Authority [1999] a mother claimed that the health authority had been negligent by discharging a man with personality disorder who subsequently killed her child. However, the Court of Appeal dismissed the case as the man had not specifically threatened that particular child (Agyapong 2009).

Frank's clinician should make a risk assessment, since other factors are also involved. An evidencebased tool such as the Structured Assessment of Violence Risk in Youth (SAVRY) could be particularly useful. The presence of autism spectrum disorder could work either way. The murderous thoughts may represent a concrete 'black or white' internal response to peer problems and consequent difficulty in emotional regulation, but little actual risk of carrying out violent acts. On the other hand, the lack of empathy associated with autism spectrum disorder may increase risk.

Ultimately, the lack of any history of aggression or forensic history (a significant risk factor for violence), as well as lack of current intent or threat, may tip the balance towards not sharing the information with authorities. However, the clinician should remain vigilant in case the level of intent or threat changes. Furthermore, it would still be useful to encourage Frank to have information shared with his parents, who may be well positioned to more closely monitor and support him.

\section{Risk from others}

Finally, let us consider Katie, the 14-year-old who discloses that a 19-year-old man had sent her sexually related messages and then had sex with her while she was drunk. Various factors would indicate abuse (Box 3): the significant age difference, the use of alcohol, and Katie being an age where her maturity to consent is questionable. This, and that Katie is under 16, indicates that the abuse is also criminal, while the sending of sexually elated messages suggests child exploitation and grooming.

Although the argument to breach confidentiality is particularly strong here to ensure appropriate safeguarding, it is worth reflecting on the various principles listed in Table 2 in order to appreciate the process. On one hand, there is the consideration of preserving engagement and therapeutic rapport, particularly important given Katie's eating disorder and the associated risks. Even in cases 
BOX 3 GMC guidelines on the need for reporting

The following factors concerning possible sexual abuse would indicate the need for reporting:

- the young person is too immature to understand or consent

- children under 13 years old are legally considered to be unable to consent to sexual activity

- significant differences in age, maturity or power between the young person and the sexual partner

- the young person's sexual partner having a position of trust or having a history of abusive relationships with children

- the use of force or the threat of force, pressure, bribery or payment

- the use of drugs or alcohol to influence a young person

(GMC 2007)

of potential child abuse, the GMC still notes the relative value of confidentiality: 'although it may seem that parents would be the obvious people to disclose to in these circumstances, doctors should consider the potential adverse consequences. Doctors must also consider the impact that such a disclosure and its consequences could have on other young people and their trust in doctors' (GMC 2015). This consequentialist position is shared by Gillon (Williams 1987), whereas Roche argues more deontologically that informationsharing [...] carries the risk of overwhelming any concern for children's rights and family privacy $[. .$.$] in a way that so clearly ignores the$ complex reality of children's lives and their voices' (Roche 2008).

On the other hand, breaching confidentiality would allow services (e.g. police and children's services) to intervene and thus hopefully reduce the risk to both Katie and, potentially, others now and in the future. In situations of child abuse, particularly given the difference in the power dynamic, the child may not be in a position to adequately protect themselves from the risk of further abuse by a coercive perpetrator. Furthermore, there are also the rights of others to consider: first, those of her parents, who have an important role in safeguarding; second, there is the issue of public interest, i.e. other people's rights to be protected from the 19-year-old man, either victims currently being abused, or potential victims at risk in the future.

Overall, GMC guidance is clear:

'Your first concern must be the safety of children and young people. You must inform an appropriate person or authority promptly of any reasonable concern that children or young people are at risk of abuse' (GMC 2007: p. 25);

'if a child or young person is involved in abusive or seriously harmful sexual activity, you must protect them by sharing relevant information with appropriate people or agencies, such as the police or social services' (GMC 2007: p. 27).

The guidance Working Together to Safeguard Children explicitly states that:

'fears about sharing information cannot be allowed to stand in the way of the need to promote the welfare and protect the safety of children [...] If a professional has concerns about a child's welfare and believes they are suffering or likely to suffer harm, then they should share the information with local authority children's social care' (Department for Education 2015: p. 17).

The need to ensure appropriate informationsharing between agencies involved in child protection has been highlighted by several highprofile cases and reports on child abuse. For example, the Laming inquiry which followed the Climbié case noted that more effective communication, interagency working and information management would eventually lead to better outcomes for children (Department of Health 2003b).

Interestingly, there is some discrepancy between the GMC guidance relating to competent children as opposed to competent adults. The guidance for adults advises that, although doctors should encourage patients to consent to disclosures necessary for their protection, they should 'usually abide by a competent adult patient's refusal to consent to disclosure, even if their decision leaves them, but nobody else, at risk of serious harm' (GMC 2009: p. 21). The greater onus on reporting child abuse may reflect significantly greater public interest in reporting it than in keeping it confidential. This would reflect the risks to the child in question, the potential or actual risks to other children and the overall vulnerability of children, even if they happen to be competent. Therefore, in Katie's case, where child abuse and criminal behaviour are implicated, GMC guidance would advise breaching confidentiality to children's services, and ultimately the police, to help ensure protection for her and, potentially, others.

\section{Practical aspects}

Confidentiality should be one of the first issues raised when initially meeting a young person and their parents; this helps them understand the principles from the start (Lehrer 2007; Tebb 2011). Such transparency makes it easier if 
confidentiality has to be breached in the future and may help protect longer-term therapeutic rapport and engagement (Ford 2004). Despite this, only 3\% of parents said their general practitioner (GP) had discussed with them confidentiality in relation to their adolescent children (Magnusson 2007).

\section{Structuring sessions}

Confidentiality concerns should influence how clinicians structure their sessions with young people if parents or carers are also involved. One model consists of breaking the session into distinct components: time with the young person alone, time with parents (or carers) alone and time with the family together.

Protected individual time with the young person maximises their opportunity to confide important but sensitive issues that could help determine the support and treatment offered. However, Kapphahn et al (1999) found that 34\% of boys and $43 \%$ of girls with high depressive symptom scores, and $25-41 \%$ of youth reporting substance use, high stress levels, physical abuse or sexual abuse, were not given an opportunity to speak privately with their doctor. The risks of future non-attending due to concerns over confidentiality have been previously discussed.

Protected time just for parents gives them the opportunity to share information or raise concerns that it would be inappropriate or distressing for their child to hear.

Time with the young person and their parents together allows information to be shared both ways, as well as enabling psychoeducation and discussions about the care plan. It also gives an opportunity to create a safe, supported space to encourage communication between the young person and the parents (Ford 2007). This is particularly important given the evidence that many girls who cite concerns about confidentiality as a reason for future nonattendance reported unsatisfactory communication with their parents (Lehrer 2007).

Evidence supports such a model. Roughly half of the adolescents in one online survey believed a parent's presence (or absence) had an effect on clinical conversations about their health (Gilbert 2014). Furthermore, the mean number of topics discussed was significantly higher when a young person was seen both individually and with family (4.11 topics), as opposed to only being seen with family (2.76 topics). The mean number of topics for individual-only sessions was 3.16 , which, although not significantly different, implies that the splitsession approach results in the best coverage of topics. The researchers also found that the topics most likely to be raised in individual time included mental health, stress, drugs and alcohol, and difficulties at school, problems frequently encountered in CAMHS.

\section{Accidental disclosure}

One occasion on which information is sometimes unwittingly shared is when letters to GPs are copied to parents. To avoid this pitfall, check with the competent young person each time whether they want any information to be excluded. They may actually consent for information to be conveyed to the GP, but not to their parents. If parents do not need to know, but the GP does, consider writing the GP a separate letter or contacting them by phone.

\section{Weighing the decision and making the disclosure}

When initially considering whether to breach confidentiality, negotiation could be used. For example, a teenager whose weight is dropping and who confides early signs of an eating disorder may agree to gain weight on a prescribed schedule and attend regular visits until you are assured that he or she has the problem under control. Sometimes it is useful to set up an agreed 'if, then' scenario. For example, 'If your weight drops below the $x$ th percentile or I feel you are in danger, I will need to raise the issue with your parents' (Jellinek 2010).

Finally, the clinician has weighed up the pros and cons, the rights and the consequences, and has determined that on balance, confidentiality should be breached to parents and/or other authorities. Now what? Box 4 lists various practical aspects of disclosure. One qualitative survey found that adolescents generally wanted their doctor to ask them before telling a parent and to give them the opportunity to tell the parent themselves (Carlisle 2006).

\section{Conclusions}

We have explored how ethical, legal and regulatory principles can be applied to dilemmas relating to confidentiality that present to CAMHS services. It is useful to bear in mind deontological positions and individuals' rights, as well as analysing the consequential benefits and harms of disclosure versus maintaining confidentiality. Research has usefully shown the importance of confidentiality in helping young people access and engage with services. However, decisions are often complex, and colleagues may well vary in their viewpoints. Ultimately, in negotiating the minefield of confidentiality clinicians are significantly helped by reflecting thoughtfully on the various issues presented by a case and carefully documenting the reasons for their actions. 
BOX 4 Some principles and practical aspects of disclosure

\section{General principles}

- Tell the young person and/or family what you propose to disclose and why, unless that would significantly undermine the purpose or increase the risk of harm

- Help them to understand the importance and benefits of sharing information, and reflect on the potential costs, so that ways to minimise them can be considered

- Consider any views given by them on why you should not disclose the information

- Appreciate that young people and families may understandably worry, particularly if they think they will be denied help, blamed or made to feel ashamed, or have had bad experiences or fear contact with the police or Social Services

- Ask the young person for consent to the disclosure, if you judge them to be competent; even if not competent, ascertain their views on what information should be disclosed to whom, and how, and try to accommodate these views

- Do not delay information-sharing if delay would increase the risk to the child or other children

- Disclose the minimum information necessary to protect or benefit the child: information-sharing should be proportionate to the risk of harm

- Disclose only to those who need to know
- If in doubt whether to share information against the child's or family's wishes, seek advice from a senior colleague, a named doctor for child protection, or your organisation's Caldicott guardian; you could also discuss the case anonymously with children's services to get their initial opinion; bear in mind that a risk might become apparent only when a number of people with niggling concerns share them

- Document any decisions made, including the reasons behind them

When disclosing to parents

- Generally encourage young people to share information, where appropriate, with their parents and to involve them in making important decisions

- Ask whether they would like to disclose the information themselves or whether they would like you do it for them; if the latter, ask whether they would like to be present or not

- Ask the child how they would like to frame the information; alternatively, explain what you are going to say and ask them to suggest how they might edit it

- Have a moment with child and parents all present before the session ends in order to evaluate how everyone has responded

(Taylor 1989; Sullivan 2002; GMC 2007, 2009; Jellinek 2010; Jackson 2014)

\section{Acknowledgements}

I would like to thank Dr Adrian Raby (Clinical Lecturer in Medical Ethics, Imperial College London) and Dr Shereen Haffejee (Consultant Child and Adolescent Psychiatrist and Named Doctor for Safeguarding Children, Surrey and Borders Partnership NHS Foundation Trust) for their advice.

\section{References}

Agyapong VIO, Kirrane R, Bangaru R (2009) Medical confidentiality versus disclosure: ethical and legal dilemmas. Journal of Forensic and Legal Medicine, 16: 93-6.

Applewhite LW, Joseph MV (1994) Confidentiality: issues in working with self-harming adolescents. Child and Adolescent Social Work Journal, 11: 279-94

Beauchamp TL, Childress JF (2001) Principles of Biomedical Ethics. Oxford University Press.

MCO answers

1 c 2 a 3 e 4 c 5 e
Carlisle J, Shickle D, Cork M, et al (2006) Concerns over confidentiality may deter adolescents from consulting their doctors: a qualitative exploration. Journal of Medical Ethics, 32: 133-7.
Cave E (2009) Adolescent consent and confidentiality in the UK. European Journal of Health Law, 16: 309-31.

Cheng T, Savageau J, Sattler A, et al (1993) Confidentiality in health care: a survey of knowledge, perceptions, and attitudes among high school students. JAMA, 269: 1404-7.

Department of Health (2003a) Confidentiality: NHS Code of Practice. Department of Health.

Department of Health (2003b) The Victoria Climbié Inquiry: Report of an Inquiry by Lord Laming (Cm5730). TSO (The Stationery Office)

Department for Education (2015) Working together to Safeguard Children: A Guide to Inter-Agency Working to Safeguard and Promote the Welfare of Children. TSO (The Stationery Office).

Duncan RE, Vandeleur M, Derks A, et al (2011) Confidentiality with adolescents in the medical setting: what do parents think? Journal of Adolescent Health, 49: 428-30.

Erikson EH (1968) Identity: Youth and Crisis. W. W. Norton.

Evans E, Hawton K, Rodham K, et al (2005) The prevalence of suicidal phenomena in adolescents: a systematic review of population-based studies. Suicide and Life-Threatening Behavior, 35: 239-50.

Ford C, Millstein S, Halpern-Felsher B, et al (1997) Influence of physician confidentiality assurances on adolescents' willingness to disclose information and seek future health care. JAMA, 278: 1029-34.

Ford C, Bearman P, Moody J (1999) Foregone health care among adolescents. JAMA, 282: 2227-34

Ford C, English A, Sigman G (2004) Confidential Health Care for Adolescents: position paper of the Society for Adolescent Medicine. Journal of Adolescent Health, 35: 160-7.

Ford C (2007) More evidence supports the need to protect confidentiality in adolescent health care. Journal of Adolescent Health, 40: 199-200.

General Medical Council (2007) 0-18 Years: Guidance for all Doctors. GMC

General Medical Council (2009) Confidentiality. GMC

GMC (2015) GMC case notes: ... protecting children from abuse and neglect .... GMC (http://www.gmc-uk.org/gmpinaction/case-studies/ sarah/case-notes). Accessed 18 Sept 2015.

Gilbert AL, Rickert VI, Aalsma MC (2014) Clinical conversations about health: the impact of confidentiality in preventive adolescent care. Journal of Adolescent Health, 55: 672-7.

Guedj M, Sastre MTM, Mullet E, et al (2009) Is it acceptable for a psychiatrist to break confidentiality to prevent spousal violence? International Journal of Law and Psychiatry, 32: 108-14.

Hawton K, Saunders K, O'Connor RC (2012) Self-harm and suicide in adolescents. Lancet, 379: 2373-82.

Iltis AS (2010) Toward a coherent account of pediatric decision making. Journal of Medicine and Philosophy, 35: 526-52.

Jackson MK, Burns KK, Richter MS (2014) Confidentiality and treatment decisions of minor clients: a health professional's dilemma \& policy makers challenge. SpringerPlus, 3: 320

Jellinek MS (2010) As child grows, so does need for confidentiality. Pediatric News, 44 (4): 20

Kant I (1964) Groundwork of the Metaphysic of Morals. Harper and Row Publishers.

Kaplan DW, Calonge N, Guernsey BP, et al (1998) Managed care and school-based health centers: use of health services. Archives of Pediatrics \& Adolescent Medicine, 152: 25-33.

Kapphahn CJ, Wilson KM, Klein JD (1999) Adolescent girls' and boys' preferences for provider gender and confidentiality in their health care. Journal of Adolescent Health, 25: 131-42.

Klein J, Wilson K, McNulty M, et al (1999) Access to medical care for adolescents: results from the 1997 Commonwealth Fund Survey of the Health of Adolescent Girls. Journal of Adolescent Health, 25: $120-30$. 
Lehrer JA, Pantell R, Tebb K, et al (2007) Forgone health care among U.S. adolescents: associations between risk characteristics and confidentiality concern. Journal of Adolescent Health, 40: 218-26.

Logan DE, King CA (2002) Parental identification of depression and mental health service use among depressed adolescents. Journal of American Academy of Child and Adolescent Psychiatry, 41: 296-304.

Magnusson J, Oakley L, Townsend J (2007) Parents' views on confidentiality and health advice for adolescents in general practice. Primary Health Care Research \& Development, 8: 121-7.

Mill JS (1863) Utilitarianism. Reprinted 1998. Oxford University Press.

Rae WA, Sullivan JR, Pena Razo N, et al (2002) Adolescent health risk behaviour: when do pediatric psychologists break confidentiality? Journal of Pediatric Psychology, 27: 541-9.

Reddy DM, Fleming R, Swain C (2002) Effect of mandatory parental notification on adolescent girls' use of sexual health care services. JAMA, 288: 710-4

Robshaw M, Smith J (2004) Concerned about confidentiality? The child protection jigsaw. Paediatric Nursing, 16 (5): 36-8.

Roche $J(2008)$ Children's rights, confidentiality and the policing of children. International Journal of Children's Rights, 16: 431-56.

Sullivan JR, Ramirez E, Rae WA, et al (2002) Factors contributing to breaking confidentiality with adolescent clients: a survey of pediatric psychologists. Professional Psychology: Research and Practice, 33 396-401.

Sullivan JR, Moyer MS (2008) Factors influencing the decision to break confidentiality with adolescent students: a survey of school counselors. Journal of School Counseling, 6 (24).

Taylor L, Adelman HS (1989) Reframing the confidentiality dilemma to work in children's best interests. Professional Psychology: Research and Practice, 20: 79-83.

Tebb K (2011) Forging partnerships with parents while delivering adolescent confidential health services: a clinical paradox. Journal of Adolescent Health 49: 335-6.

Thrall J, McCloskey L, Ettner S, et al (2000) Confidentiality and adolescents' use of providers for health information and for pelvic exams. Archives of Pediatrics \& Adolescent Medicine, 154: 885-92.

Williams R, Hari Singh T, Naish J, et al (1987) Medical confidentiality and multidisciplinary work: child sexual abuse and mental handicap registers. BMJ, 295: 1317.

\section{Cases}

Gillick v West Norfolk and Wisbech Area Health Authority [1986] AC 112.

Palmer v Tees Health Authority [1999] Lloyd's Rep Med 151

$R$ (Axon) v Secretary of State for Health [2006] EWCA 37.
MCQs

Select the single best option for each question stem

1 Deontological ethical philosophy argues that:

a the consequences of an action are what defines whether it is ethical or not

b we can never know exactly the subjective experience of other beings

$c$ the morality of an action relates to the action itself and not its consequences

$\mathrm{d}$ free will is impossible

e consciousness is an illusion.

2 Article 8(1) of the European Convention on Human Rights specifies that:

a everyone has the right to have their private and family life respected

b everyone has the right to freedom of thought, conscience and religion

c everyone has the right to liberty and security

$\mathrm{d}$ everyone has the right to freedom of expression

e everyone's right to life shall be protected by law.
3 The case law that most explicitly relates to a young person's rights to confidentiality is:

a Gillick v West Norfolk and Wisbech Area Health Authority

b Palmer v Tees Health Authority

c Re R (A Minor)

d Re W (A Minor)

e $R(A x o n) v$ Secretary of State for Health.

\section{Research shows that:}

a a young person's belief that information will invariably be shared with parents does not affect the likelihood that they will disclose risky behaviours or attend healthcare services

b parents generally believe that they do not have a right to know about risks relating to their adolescent children

c aspects of confidentiality are rarely discussed with adolescent patients and their families in primary care

$\mathrm{d}$ when deciding whether to breach confidentiality, clinicians prioritise the risk of patient disengagement more than the seriousness, frequency, intensity and duration of the risky behaviour

e ethnic and religious factors rarely influence parents' attitudes towards their child's right to confidentiality

5 Which factor does not support the protection of confidentiality in a competent young person?

a confidentiality may increase the likelihood of the young person disclosing information that helps guide treatment

$\mathrm{b}$ the individual has a right to autonomy, the development of which constitutes an important part of adolescence

c confidentiality may help to protect or enhance the therapeutic relationship and service engagement

d society has an interest in maintaining trust between doctor and patient, and so confidential medical care is recognised in law as being in the public interest

e parental rights to know information in order to help safeguard their child. 